\title{
Retinal and preretinal localisation of epidermal growth factor, transforming growth factor alpha, and their receptor in proliferative diabetic retinopathy
}

\author{
Bhartiben Patel, Paul Hiscott, David Charteris, Joanne Mather, David McLeod, Mike Boulton
}

\begin{abstract}
A number of growth factors have been implicated in the development and perpetuation of preretinal fibrovascular membranes in patients with proliferative diabetic retinopathy (PDR). The aim of this study was to determine the potential role of epidermal growth factor (EGF), transforming growth factor alpha (TGF- $\alpha$ ), and their receptor (EGF-R) in PDR development. Immunostaining for EGF, TGF- $\alpha$, and EGF-R was compared between normal retina, $P D R$ retina, and $P D R$ preretinal membranes. Weak staining for EGF and EGF-R was observed throughout the neural retina from non-diabetic eyes while weak to moderate staining for TGF- $\alpha$ was observed in the ganglion cell layer and the inner and outer nuclear layers. In contrast, intense staining for EGF and TGF- $\alpha$ and moderate staining for EGF-R were observed throughout the PDR retina. Immunoreactivity for EGF, TGF- $\alpha$, and EGF-R was seen in the majority of the 11 excised membranes studied and, though variable, was generally greater than that observed in normal retinas. These results suggest an autocrine/paracrine role for EGF, TGF- $\alpha$, and EGF-R in PDR.
\end{abstract}

(BrF Ophthalmol 1994; 78: 714-718)

Proliferative diabetic retinopathy (PDR) is characterised by preretinal neovascularisation and fibrosis ultimately leading to vitreous haemorrhage and traction retinal detachment. It is likely that growth factors (which are known to modulate cell proliferation, cell migration, and the production of proteolytic enzymes, collagen, and other extracellular matrix molecules) are involved in the various steps of this disease process. ${ }^{1}$ Support for growth factor involvement comes from the analysis of vitreous gel specimens which demonstrate increased levels of a variety of growth factors in PDR compared with gel removed from eyes not undergoing a proliferative response. ${ }^{2-5}$ However, it is uncertain whether these growth factors originate from within the pathological tissue mass and thus act in a paracrine/autocrine fashion or whether they are derived from some other source (that is, systemically or from other cells/tissues within the eye such as the retina).

The aim of this study was to determine the potential role in PDR of one growth factor family - namely epidermal growth factor (EGF) and transforming growth factor alpha (TGF- $\alpha$ ), which have a $40 \%$ homology and which act through the same receptor ${ }^{6-8} \mathrm{We}$ investigated (a) whether EGF/TGF- $\alpha$ and their receptor are present in PDR epiretinal membranes (ERMs)/ preretinal membranes (PRMs), (b) how expression changed compared with normal retina, and (c) whether EGF/TGF- $\alpha$ are localised to specific cell types within the PRMs. We chose the EGF/ TGF- $\alpha$ family since both growth factors are potent mitogens which stimulate cellular proliferation and differentiation of a wide variety of ectodermal and mesodermal cells and have been demonstrated to play a significant role in wound healing. ${ }^{9}$ We included investigation of the EGF/ TGF- $\alpha$ receptor since the activity of any growth factor is dependent on the presence of the appropriate receptor on the target cell.

\section{Materials and methods \\ HUMAN TISSUES}

Controls

Sections of human skin were used as control tissues for EGF, TGF- $\alpha$, and EGF-R immunohistochemical procedures. Optic nerve stumps attached to the globes (see below) were employed as control tissue for glial fibrillary acidic protein (GFAP) immunohistochemistry.

\section{Normal retina}

Eleven human eyes with no known ophthalmic disease were provided by the National Disease Research Interchange (NDRI), Philadelphia, USA and the Manchester Royal Eye Hospital Eye Bank. Donor age ranged from 19 to 88 years (mean 69 years). Postmortem time ranged from 1 to 11 hours (mean 4.6 hours; five eyes were equal or less than 2 hours post mortem).

\section{$P D R$ retina}

Four fragments of retinal tissue were obtained from three eyes during closed microsurgery for tractional complications of PDR. The retinal pieces and associated epiretinal membranes were removed as a relieving retinectomy in order to permit retinal reattachment.

\section{Preretinal membranes}

Eleven fibrovascular vitreous or epiretinal mem- 
branes from ten eyes were obtained during closed microsurgery for PDR.

\section{Methods}

Skin, retinal fragments, and PDR membranes were fixed in $4 \%$ neutral buffered formalin for a minimum of 12 hours before being embedded in paraffin wax. Eyes were fixed in $4 \%$ neutral buffered formalin within 12 hours post mortem. The globes were carefully dissected and portions of retina/choroid/sclera were embedded in paraffin wax.

\section{Primary antibodies}

All antibodies were diluted in Tris buffered saline (TBS) $\mathrm{pH} 7.6$ containing $0.2 \%$ normal goat serum. Details of the antibodies are as follows: mouse antisera to human GFAP (Sigma), a marker for glial cells, was used at a dilution of $1 / 100$; rabbit antisera to factor VIII (Dako), a marker for endothelial cells, was used at a dilution of $1 / 100$; a rabbit polyclonal antibody to recombinant human EGF (Oncogene Science), which reacts specifically with human EGF and shows no cross reactivity with TGF- $\alpha$ was used at a dilution of $1 / 100$; a mouse monoclonal antibody raised against residues 34-50 of TGF- $\alpha$ (Oncogene Science), which reacts specifically with TGF- $\alpha$ and shows no cross reactivity with EGF was used at a dilution of $1 / 100$; a mouse monoclonal antibody raised against residues 985-996 of the EGF receptor (Sigma) which specifically recognises the intracellular domain of the EGF receptor, was used at a dilution of $1 / 50$; goat anti-mouse and anti-rabbit IgG conjugated to biotin (Sigma) were used as secondary antibodies at a dilution of $1 / 150$.

\section{Immunostaining}

Serial sections, $4 \mu \mathrm{m}$ thick, of the wax embedded specimens were dewaxed in xylene and rehydrated through a series of graded alcohols. The sections were washed in TBS and incubated with $0 \cdot 1 \%$ chymotrypsin in TBS for 20 minutes at $37^{\circ} \mathrm{C}$. The sections were washed in TBS and incubated in normal goat serum (Sigma) for 10 minutes to block non-specific binding. Excess serum was removed by washing in TBS and the primary antibody was applied for 1 hour at room temperature. Following three 10 minute washes in TBS, samples were exposed to an anti-mouse/ rabbit IgG conjugated to biotin for 1 hour at room temperature. The sections were washed three times for 10 minutes each in TBS and then incubated with an avidin-biotin alkaline phosphatase reaction complex (Dako). Following extensive washing, antibody binding was visualised using a naphthol phosphate/fast red substrate mixture which resulted in the formation of a red product (endogenous alkaline phosphatase activity was blocked using levamisole at this stage). In some instances immunostained sections were counterstained with haematoxylin to enhance examination. Selected non-immunostained sections were stained with haematoxylin and eosin to permit evaluation of the overall morphology of the specimens.
Negative controls included (1) omission of the primary antibody, and (2) substitution of the primary antibody with an affinity purified mouse IgG at the same concentration as the primary antibody.

\section{Assessment of immunostaining}

The degree and pattern of immunostaining both within and between specimens was assessed by standard light microscopy. The intensity of staining was graded qualitatively as background, minimal, moderate, or intense; background staining was the level of staining seen in the negative controls, 'intense' corresponding to the highest level of immunoreactivity observed in the positive controls.

\section{Results}

CONTROLS

Immunoreactivity for EGF, TGF- $\alpha$, and EGF-R was seen in the epidermal layer of normal human skin. The non-neural, non-vascular components of the optic nerve exhibited GFAP immunoreactivity. The immunostaining was abolished in sections processed with omission or substitution of the primary antibody (Fig 1F).

\section{NORMAL RETINA}

Immunostaining for EGF, TGF- $\alpha$, and EGF-R was observed in the majority of the retinas examined (Fig 1A, B; Table 1). EGF demonstrated weak to moderate diffuse staining throughout the neural retina (7/11) and within the RPE (5/11). TGF- $\alpha$ demonstrated weak to moderate staining throughout the neural retina in 10/11 eyes. Staining intensity was greatest in the ganglion cell layer, inner nuclear layer, and outer nuclear layer. Isolated cells within the inner nuclear layer exhibited the highest intensity of staining (Fig 1B). Immunolocalisation of TGF- $\alpha$ was not observed in either the RPE or the choroid. Weak to moderate staining for EGF-R staining was observed throughout the neural retina and RPE in 8/11 of the eyes examined. Some intracellular staining was observed for both peptide growth factors. GFAP staining in the neural retina varied between specimens; $1 / 11$ exhibited no staining, $7 / 11$ very weak staining, and 3/11 intense staining. Staining was either in the peripheral retina (adjacent to microcystoid changes) or in the inner retinal layers (astrocytic staining). There was no correlation between staining pattern/intensity for the antibodies used and either donor age or postmortem time.

\section{PDR RETINA}

The retinal fragments consisted of detached full thickness neuroretinal tissue (three eyes) or neuroretina plus RPE (one eye). All of the sensory retinal pieces showed variable gliosis and intense GFAP immunolabelling.

Intense immunoreactivity for EGF and TGF- $\alpha$ was observed throughout all of the excised retinal fragments (Fig 1C, D; Table 1). 


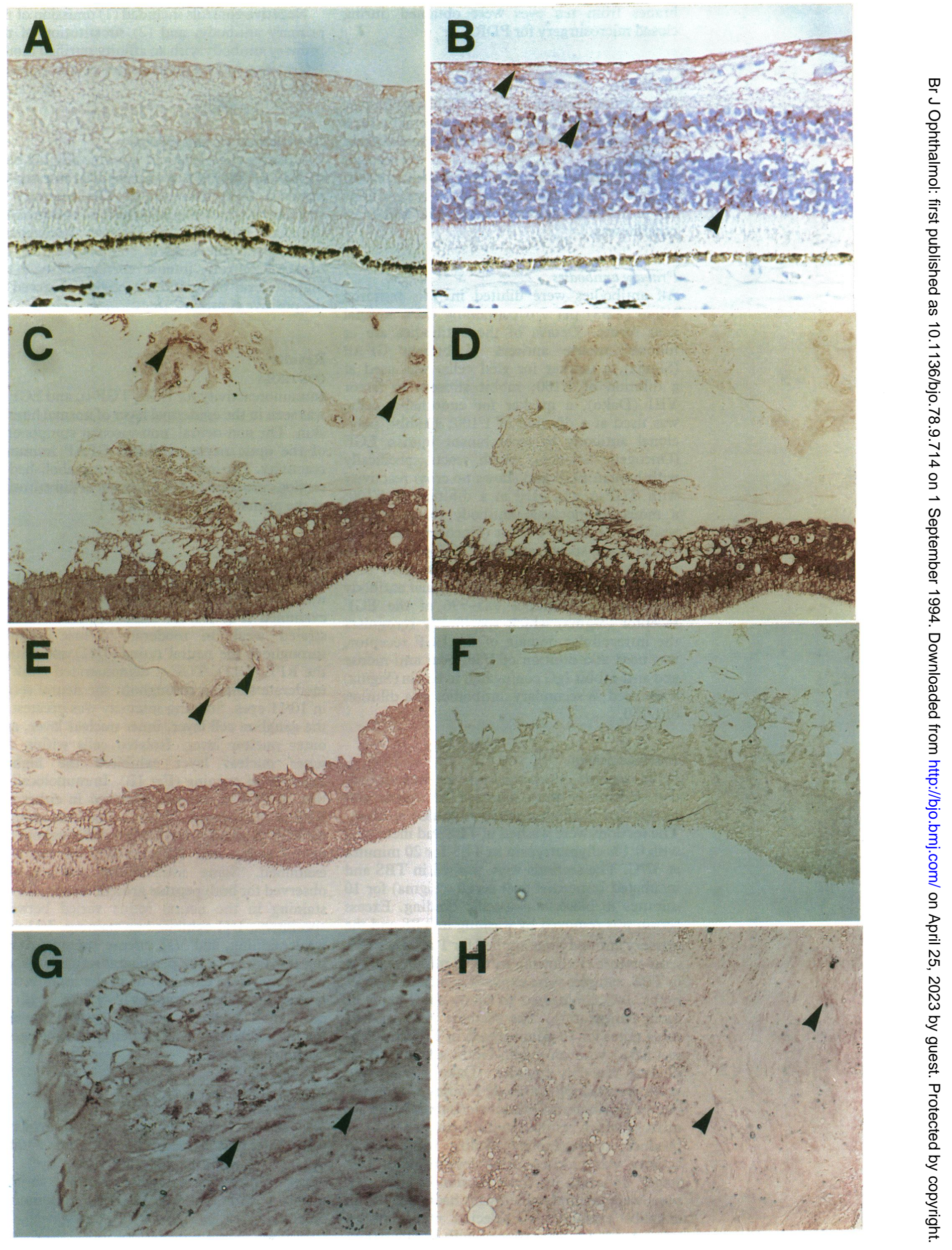


Table 1 Immunostaining characteristics of epidermal growth factor $(E G F)$, transforming growth factor alpha $(T G F-\alpha)$, and epidermal growth factor receptors $(E G F-R)$ in normal retina, $P D R$ retina, and $P D R$ membranes

\begin{tabular}{|c|c|c|c|}
\hline Specimen & $E G F$ & $T G F-\alpha$ & $E G F-R$ \\
\hline \multicolumn{4}{|l|}{ Normal retina: } \\
\hline & - & + & + \\
\hline 2 & + & - & - \\
\hline 3 & ++ & ++ & + \\
\hline 4 & + & ++ & + \\
\hline 5 & + & + & + \\
\hline 6 & - & + & - \\
\hline 7 & + & + & - \\
\hline 8 & - & + & + \\
\hline 9 & ++ & ++ & + \\
\hline 10 & - & + & + \\
\hline $\begin{array}{l}11 \\
\text { PDR rina: }\end{array}$ & + & + & ++ \\
\hline \multicolumn{2}{|l|}{ PDR retina: } & +++ & +++ \\
\hline 2 & +++ & +++ & ++ \\
\hline $3^{\star}$ & +++ & +++ & +++ \\
\hline $4^{\star}$ & $++t$ & +++ & +++ \\
\hline \multicolumn{4}{|c|}{ PDR membranes: } \\
\hline $\begin{array}{l}1 \\
2\end{array}$ & +++ Dcgv & $+++\mathrm{Fv}$ & $++F c g v$ \\
\hline 3 & $+++\mathrm{Fv}$ & $+++\mathrm{Fv}$ & $+++\mathrm{Fv}^{\circ}$ \\
\hline $\begin{array}{l}4 \\
5\end{array}$ & $\begin{array}{l}\text { nd } \\
+++ \text { Dgv }\end{array}$ & $+++\operatorname{Dcgv}$ & + + Dcg \\
\hline 6 & +++ Fgv & + Dcgv & + Dcgv \\
\hline $\begin{array}{l}7 \\
8\end{array}$ & $\begin{array}{l}+\mathrm{Fv} \\
++\mathrm{Fcv}\end{array}$ & $\overline{+}++F \mathbf{F}$ & $\begin{array}{l}+\mathrm{Fcv} \\
++\mathrm{Fcv}\end{array}$ \\
\hline 9 & $++\mathrm{Fc}$ & $++\mathrm{Fv}$ & + Dcgv \\
\hline 10 & $+++\mathrm{Fv}$ & $++F v$ & $+F_{c v}$ \\
\hline 11 & $+F c$ & & \\
\hline
\end{tabular}

$\mathrm{PDR}=$ proliferative diabetic retinopathy .

$-=$ Background,$+=$ weak positive,$++=$ moderate, $+++=$ intense.

$\mathrm{D}=$ diffuse staining, $\mathrm{F}=$ focal staining to either vascular cells $(\mathrm{v})$, or cells in the collagenous matrix (c), or glial cells (g). nd $=$ Not done.

$\star$ These membranes were excised from the same eye.

In addition, intense (three specimens) or moderate (one specimen) immunostaining for EGF-R was seen in these fragments (Fig $1 E$; Table 1). Overall the pattern of growth factor and EGF-R staining was diffuse; however, in some retinal fragments the vascular endothelium and inner retinal layers exhibited even more intense staining than the rest of the tissue.

\section{PRERETINAL MEMBRANES}

General morphological and immunohistochemical features

Sufficient tissue was available in the 11 excised

Table 2 Morphological and cellular characteristics of preretinal membranes (PRM)

\begin{tabular}{|c|c|c|c|}
\hline PRM & Cellularity & $G F A P^{\star}$ & Factor VIIIt \\
\hline 1 & Hypocellular & nd & + \\
\hline 2 & Fibrocellular & +++ & + \\
\hline 3 & Fibrocellular & + & + \\
\hline 4 & Fibrocellular & - & + \\
\hline 5 & Fibrocellular & ++ & + \\
\hline 6 & Fibrocellular & ++ & + \\
\hline 7 & Fibrocellular & + & + \\
\hline 8 & Fibrocellular & +++ & + \\
\hline 9 & Fibrocellular & ++ & + \\
\hline 10 & Hypocellular & - & + \\
\hline 11 & Hypocellular & nd & + \\
\hline
\end{tabular}

membranes to permit immunostaining for GFAP in nine specimens, EGF in 10 specimens, TGF- $\alpha$ in nine specimens, and EGF-R in 10 specimens.

All of the 11 preretinal membranes were fibrovascular in nature and the fibrous component of the membranes contained isolated cells which were usually fibroblast-like or inflammatory cells. Nevertheless, there was considerable variation within and between membranes in the number and distribution of cells.

Immunoreactivity for EGF, TGF- $\alpha$, and EGF-R was seen in $9 / 10,7 / 9$, and $9 / 10$ of the membranes respectively (Fig $1 \mathrm{G}, \mathrm{H}$; Table 1). The intensity of the immunostaining for each of the peptides varied markedly between and within specimens. Intense immunostaining was seen in six specimens for EGF, four specimens for TGF- $\alpha$, and two specimens for EGF-R. In general the fibrous component of the membranes exhibited much weaker immunoreactivity for EGF, TGF- $\alpha$, and EGF-R than cellular areas. As with retinal specimens, variable intracellular EGF, TGF- $\alpha$, and EGF-R immunostaining was observed in the PDR membranes.

\section{Specific cell types}

Vascular endothelial cells were identified in all membranes by factor VIII staining (Table 2). The endothelial cells exhibited EGF immunoreactivity in $7 / 10$ specimens, in four of which the staining was intense (Table 1). TGF- $\alpha$ immunoreactive endothelium was seen in 7/9 specimens, in four of which the immunostaining was intense. EGF-R was found in endothelial cells in 9/10 specimens (one showing intense, four moderate, and four weak staining).

Isolated cells in fibrous tissue showed immunolabelling for EGF in $6 / 10$ specimens (three intensely and one moderately) and TGF- $\alpha$ in 2/9 (one intensely). EGF-R immunoreactivity was observed on isolated cells in $7 / 10$ membranes, in three of which the staining was moderate.

Variable GFAP staining was observed in 7/11 specimens (aggregates of glial cells in six and isolated glial cells in one) (Table 2). Three glial cell aggregates showed intense (two membranes) or moderate (one membrane) immunostaining for EGF while TGF- $\alpha$ labelling was observed in two (one intense; one weak) preretinal glial cell aggregates. Weak (two specimens) or moderate (one specimen) EGF-R staining was found in three glial clusters.

\section{Discussion}

Our results demonstrate weak to moderate immunoreactivity for EGF, TGF- $\alpha$, and EGF-R in the majority of normal human adult retinas. Lack of immunostaining in a few retinas may reflect variation between individuals, variation within the staining procedure, or both. This is

Figure 1 Photomicrographs demonstrating immunostaining of normal retina $(A, B), P D R$ retina $(C-F)$, and $P D R$ membranes $(G, H)$ for $E G F(A, C, G)$, $T G F-\alpha(B, D), E G F-R(E, H)$, and negative control $(F)$. Diffuse, weak staining for $E G F$ can be seen throughout the normal retina $(A)$. TGF- $\alpha$ staining in the normal retina is primarily localised to the ganglion cell layer and the inner and outer nuclear layers $(B$, arrows). Intense immunostaining for $E G F, T G F-\alpha$, and $E G F-R$ is observed throughout the PDR retina and in the membrane vessels for EGF and EGF-R (C-E, arrows). Very weak background staining can be observed in the negative control $(F)$. Moderate to intense staining for $E G F$ is shown by fibroblast-like cells within the fibrous component of a membrane $(G$, arrows $)$. Weak to moderate $E G F-R$ is exhibited by cells in a PDR membrane $(H$, arrows $)$. Magnification: $A, B \times 100 ; C-E, H \times 75 ; G \times 160$. 
the first demonstration of the presence of EGF and TGF- $\alpha$ together with their receptor in the human retina in situ. These findings are supported by previous studies on other species. Steady state levels of TGF- $\alpha$ mRNA have been reported for bovine retinas ${ }^{10}$ and the EGF receptor has been localised to cultured human $\mathrm{RPE}^{11}$ and rat Mueller cells. ${ }^{12}$

Interestingly, levels of staining intensity for both peptide growth factors and their receptor were increased in full thickness neuroretinal specimens associated with PDR membranes. Furthermore, the immunoreactivity for peptides/receptors was more intense in PDR membranes than the normal retinas. It was difficult to make subjective comparisons between the immunoreactivity in PDR retinal fragments and their associated epiretinal membranes. However, focal staining in the membranes was generally equivalent to that in the PDR retina. The weak diffuse staining observed in the fibrous component of the PDR membranes may reflect peptide growth factor binding to extracellular matrix components, but the staining was considerably less than that previously reported for $\mathrm{EGF}{ }^{13}$

The role of these growth factors and their receptor in PRM pathobiology is unclear. PDR membrane formation involves cellular migration and proliferation together with extracellular matrix synthesis. ${ }^{1}$ Such cellular events are likely to be modulated by a variety of growth factors. Two such, EGF and TGF- $\alpha$, are known to be potent mitogens as well as modulating cell migration, cell differentiation, extracellular matrix synthesis/turnover, receptor transmodulation, and synthesis of other growth factors. ${ }^{6-8}$ Given that the receptor for these two peptides is present in PDR membranes it is reasonable to speculate that they are involved in the development and perpetuation of the preretinal tissue.

The origin of these growth factors remains uncertain. Such factors could be of systemic origin or be derived locally from the retina or from within the membranes themselves. It is possible that several different origins are involved. However, the observed intracellular staining within many of the cells in both the PDR retinal fragments and preretinal membranes infers local synthesis and the possible existence of an autocrine/paracrine control. This staining for EGF and TGF- $\alpha$ is unlikely to be due to internalisation of the growth factors since EGF receptor complexes undergo rapid internalisation via the endosome system resulting in rapid degradation of both the ligand and the receptor within lysosomal compartments. ${ }^{14}$ Moreover, since several different cell types (including glial and endothelial cells) labelled for EGF, TGF- $\alpha$, and EGF-R, it is possible that more than one cell type is responsible for the peptides and their receptor. Investigations of gene expression for EGF and TGF- $\alpha$ in the retina and PDR membranes may provide additional information regarding their sites of origin.

This study was funded by the Guide Dogs for the Blind Association, the Foundation for the Prevention of Blindness, and the Manchester Royal Eye Hospital Endowment Fund. We are indebted to Mr M J Lavin, Mr C L Dodd, Mr G Raymond, and Mr $P$ McCormack for their help in the provision of the surgical specimens.

1 Boulton ME, McLeod D, Garner A. Vasoproliferative retinopathies: clinical, morphogenetic and modulatory aspects. Eye 1988; 2 (suppl): S124-39.

2 Campochiaro PA, Jerdan JA, Glaser BM, Cardin A, Michels RG. Vitreous aspirates from patients with vitreo-retinopathy stimulate retinal pigment epithelial migration. Arch Stimulate retinal pigment

3 Grant M, Russell B, Fitzgerald C, Merimee TJ. Insulin-like growth factors in vitreous: studies in controls and diabetics with neovascularisation. Diabetes 1986; 35: 416-22.

4 Lutty JA, Chandler C, Bennett A, Fait C, Patz A. Presence of endothelial cell growth factor activity in normal and diabetic vitreous. Curr Eye Res 1986; 5: 9-17.

5 Sivalingham A, Keeny J, Brown GC, Benson WE, Donso L. Basic fibroblast growth factor levels in the vitreous of patients with proliferative diabetic retinopathy. Arch Ophthalmol 1990; 108: 869-72.

6 Burgess AJ. Epidermal growth factor and transforming growth factors. Bull 1989; 45: 101-24.

7 Carpenter G. Receptors for epidermal growth factor and other polypeptide mitogens. Annu Rev Biochem 1987; 56: 881-914.

8 McAvoy JW, Chamberlain CG. Growth factors in the eye Prog Growth Factor Res 1990; 2: 29-43.

9 Clemmens MJ. Cytokines. Oxford: Bios Scientific Publishers, 1991.

10 Fassio JB, Brockman EB, Jumblatt M, Greaton C, Henry JL, Geoghegan TE, et al. Transforming growth factor and its receptor in neural retina. Invest Ophthalmol Vis Sci 1989; 30: receptor in

11 Lopez JG, Chew SJ, Thompson HW, Malter JS, Insler MS, Beuerman RW. EGF cell surface receptor quantitation on ocular cells by an immunohistochemical flow cytometry technique. Invest Ophthalmol Vis Sci 1992; 33: 2053-62.

12 Roque RS, Caldwell RB, Behzadian MA. Cultured muller cells have high levels of epidermal growth factor receptors. Inves Ophthalmol Vis Sci 1992; 33: 2587-95.

13 Fredj-Reygrobellet D, Baudoin C, Negre F, Caruelle JP, Gastaud P, Lapalus P. Acidic FGF and other growth factors in preretinal membranes from patients with diabetic retinopathy and proliferative vitreoretinopathy. Ophthalmic Res pathy and proliferati

14 Ebner R, Derynck R. Epidermal growth factor and transforming growth factor- $\alpha$ : differential intercellular routing and processing of receptor ligand complexes. Cell Regul 1991; 2: 599-612. 